\title{
Genetic disorders involving molecular-chaperone genes: A perspective
}

\author{
Alberto J.L. Macario, $M D^{1,2}$, Tomas M. Grippo, $M D^{1}$, and Everly Conway de Macario, $P h D^{1}$
}

\begin{abstract}
Molecular chaperones are important for maintaining a functional set of proteins in all cellular compartments. Together with protein degradation machineries (e.g., the ubiquitin-proteasome system), chaperones form the core of the cellular protein-quality control mechanism. Chaperones are proteins, and as such, they can be affected by mutations. At least 15 disorders have been identified that are associated with mutations in genes encoding chaperones, or molecules with features suggesting that they function as chaperones. These chaperonopathies and a few other candidates are presented in this article. In most cases, the mechanisms by which the defective genes contribute to the observed phenotypes are still uncharacterized. However, the reported observations definitely point to the possibility that abnormal chaperones participate in pathogenesis. The available data open novel perspectives and should encourage searches for new genetic chaperonopathies, as well as further analyses of the disorders discussed in this article, including detection of new cases. Genet Med 2005:7(1):3-12.
\end{abstract}

Key Words: genetic chaperonopathies, defective chaperones, structural chaperonopathies, neuromuscular diseases, eye diseases.

Protein biogenesis is one of the most crucial physiological processes, ensuring the maintenance of a complete set of proteins, correctly folded, in every cellular compartment. The pathogenetic potential of failure in the mechanisms that assist protein folding and refolding is gradually capturing the attention of a growing number of investigators. However, the field is still in its initial stages, despite the fact that the major players in assisted protein folding have been under scrutiny in experimental systems for over three decades. Furthermore, a number of disorders (e.g., several neurodegenerative diseases), both in humans and in suitable experimental models, have already been linked with protein misfolding, aggregation, and precipitation. ${ }^{1-5}$ In all of these instances, the causes of the problems were defects in the protein themselves, i.e., proteinopathies, rather than deficiencies in the mechanism that assists them to fold. In contrast, we will here discuss a number of conditions in which defects in molecules that assist in protein folding, termed molecular chaperones, have been identified. In most cases, it was unclear how much the defective chaperone contributed to pathogenesis; in others, the identity of the defective molecule was not established, beyond a reported sequence similarity with a known chaperone. Nevertheless, the amount

\footnotetext{
From the ${ }^{1}$ Wadsworth Center, Division of Molecular Medicine, New York State Department of Health, ${ }^{2}$ Department of Biomedical Sciences, School of Public Health, The University at Albany (SUNY), Albany, New York.

Alberto J.L. Macario, MD, Professor; Research Physician, Wadsworth Center, Room B-749, Division of Molecular Medicine, New York State Department of Health, Empire State Plaza, PO Box 509, Albany, NY 12201-0509.

Received: September 15, 2004.

Accepted: November 1, 2004.
}

DOI: 10.1097/01.GIM.0000151351.11876.C3 and quality of the information currently available justify a serious consideration of the possibility that defective chaperones contribute to pathogenesis and may even be the primary etiology in many disorders. Some of the available information is discussed in this article, so as to provide investigators and practitioners with an introduction to this emerging discipline: the study of chaperonepathies.

\section{MOLECULAR CHAPERONES}

Molecular chaperones assist other proteins in the following ways: (1) folding during and after synthesis on the ribosome; (2) migration to the cellular locale in which they will function; (3) translocation across membranes to reach the inside of the organelle (e.g., the mitochondrion) in which they normally reside and work; and (4) refolding after partial denaturation by stressors. ${ }^{6-9}$ Chaperones also participate in disaggregation of protein aggregates, ${ }^{10-12}$ and in protein degradation: they direct those damaged or abnormal polypeptides that have little chance for proper folding to the proteolytic machinery. ${ }^{13,14}$

Many molecular chaperones are heat-shock proteins (Hsp), because their parent genes are induced by heat shock and, in some cases also by other stressors, such as heavy metals and chemicals, hormonal imbalances, and changes in $\mathrm{pH}$, pressure, or osmolarity. Chaperones and Hsp are sometimes classified according to molecular mass (a useful criterion for guiding biochemical and structural analyses) into six groups: high molecular mass, Hsp90, Hsp70, Hsp60 (chaperonins), Hsp40, and small Hsp or sHsp (kD: 100 or higher, 81-99, 65-80, 55-64, $35-54$, and 34 or lower; respectively). ${ }^{15}$ Within each group it is possible to identify families of chaperones that are evolutionarily related, for example, the Hsp70 and alpha-crystallin fam- 
ilies (the latter belongs to the sHsp group). Recently, this evolutionary criterion together with structural and functional information stored in databases have been used to propose a new classification. ${ }^{16}$ This classification reflects the great variety of the Hsp and chaperones as well as the structural similarities and phylogenetic relationships among the members of various subgroups. Furthermore, a distinction has to be made between the chaperones Hsp70(DnaK) and Hsp90 and their respective cofactors (cochaperones). ${ }^{17}$ Whereas a chaperone [e.g., Hsp70(DnaK)] binds the polypeptide in need of assistance for folding or refolding (client polypeptide or substrate), a cochaperone [e.g., Hsp40(DnaJ), a cochaperone for Hsp70(DnaK)] does not, or if it does, clientpolypeptide binding is not its main function. Lastly, a useful grouping of chaperones takes into account their ranges of different substrates: some chaperones [e.g., Hsp70(DnaK)] bind a wide range of substrates, whereas others (e.g., tubulin assembly factors) bind one or very few substrates. The latter are "dedicated chaperones." This distinction is important when considering the impact of chaperone deficiency. The occurrence of a defective dedicated chaperone can be predicted to affect a limited group of cellular functions, to be more localized, as compared with the impact of a defect in a chaperone with a wide range of substrates.

To exercise its functions, a chaperone teams up with other chaperones of the same or a different group, and forms a chaperoning complex or machine. These complexes are designated according to their components, for example, molecular chaperone machine [Hsp70(DnaK)-Hsp40(DnaJ)-nucleotide exchange factor], chaperonin type I complex (GroEL-GroES in bacteria), thermosome (between one and five subunits in archaea), and chaperonin type II-containing TCP-1 or CCT (in the eukaryotic cytosol). A team assists a polypeptide to fold or refold, or to migrate inside a cell compartment and translocate across membranes; or it delivers the polypeptide to another, different, complex (chaperoning networking) for completion of folding or for degradation.

The eukaryotic cell contains compartments possessing distinct evolutionary histories, functions, and sets of molecular chaperones. ${ }^{15}$

\section{DEFECTIVE CHAPERONES: CHAPERONOPATHIES}

In the last few years, attention has begun to be directed to disorders associated either with defective chaperones, or else with protein molecules whose primary sequences resemble those of chaperones. ${ }^{18-22}$ These pathologic conditions constitute a subset of the proteinopathies; they were reviewed, and termed chaperonepathies (now chaperonopathies), in 2002.23

Genetic or acquired defects can affect one or more of the specialized functions of the various segments or domains of a chaperone molecule. Thus, the pathologic/clinical manifestations of a chaperonepathy will depend on what domain/function is impaired or abolished. A molecular chaperone must be able to do the following: (1) recognize and bind substrate (e.g., a polypeptide in need of chaperone assistance for folding or refolding) via its substrate-binding domain; (2) interact, via its oligomerization domain, with other chaperones or cochaper- ones and cofactors with which it builds the chaperoning complex (i.e., the actual chaperone machine that will perform the folding or refolding pathway for a polypeptide, or that will assist in the formation of a multimeric assemblage of polypeptides); and (3) interact, as part of a chaperone complex, with other chaperoning and protein-degradation machines, to integrate the protein-quality control networks of the cell. It is important to bear in mind that functional domains are not necessarily formed by a single, continuous stretch of amino acids. Functional domains can also be formed by noncontiguous segments of the protein coming together by folding into a tertiary structure. Thus a mutation affecting a given domain/function may be localized at various positions in the primary structure.

In addition to these structural chaperonopathies, other types have been found in which the defect was not structural but regulatory: the expression of a chaperone gene was either increased or decreased.15,21-27 Although the suggestion was that the chaperonopathy was caused by defects in the mechanisms regulating chaperone-gene expression, it was not determined whether the gene dysregulation was the cause or the effect of the primary disease, or of senescence.

Lastly, other structural chaperonopathies are caused by posttranslational defects due either to RNA truncation, or else to protein oxidation, glycation, or other modifications. These are acquired conditions rather than hereditary ones and they tend to reach pathologic levels in aged individuals.

The ubiquitin-proteasome system (UPS) and other proteases are also involved in protein quality control. ${ }^{14}$ Degradation occurs when a protein is detected to be defective and unable to fold correctly, or to have been unfolded (e.g., partially denatured by a stressor) beyond recovery. If this quality-control mechanism fails, the abnormal or denatured polypeptides aggregate and precipitate..$^{28-30}$

\section{STRUCTURAL CHAPERONOPATHIES DUE TO GENE MUTATIONS}

In genetic chaperonopathies, the molecules affected can each be assigned to a chaperone group, for example chaperonins of group I (bacterial-type chaperonins) and group II (typical of the archaeal and eucaryal cytosols), chaperone cofactors involved in tubulin folding and microtubule biogenesis, sHsp, and peptidyl-prolyl cis-trans isomerase (PPIase).

\section{CHAPERONINS OF GROUP I}

\section{Hereditary spastic paraplegia}

The mitochondrion contains a chaperonin related to bacterial GroEL named Hsp60, and Hsp10, related to bacterial GroES. The mitochondrial Hsp60 and Hsp 10 are believed to be of bacterial origin, according to evolutionary analyses, and together they form a chaperoning machine similar to the bacterial GroEL/GroES chaperonin complex, which plays a critical role in the folding of numerous cellular proteins. ${ }^{7,31}$

The term hereditary spastic paraplegia (HSP) designates a large, heterogeneous group of human neurodegenerative dis- 
eases, in which at least 17 loci have been implicated. Five genes in these 17 loci have been cloned and sequenced. ${ }^{32}$ The protein products of at least two of these five genes, paraplegin and spastin, are thought to function as chaperones. The genes encoding human mitochondrial chaperonins Hsp60(Cpn60) and Hsp10(Cpn10) map to chromosome 2q33.1. The two genes are sited in the region where the locus SPG13 for HSP has been mapped. It was also found that SPG13 contains a mutated $h s p 60$, encoding isoleucine-72 instead of valine-72 (V72I). ${ }^{32}$ Complementation experiments in Escherichia coli showed that the human mutant gene encoding an Hsp60 with isoleucine at position 72 , together with the wild-type $h s p 10$ gene, did not rescue cells that lacked their own set of hsp60-hsp10 (groEL/ groES) genes. In contrast, the wild-type human gene and a human gene with a mutation at position 158 tested under the same conditions (both in conjunction with wild-type Hsp10) did rescue E. coli cells. These results suggest that, indeed, the mutant Hsp60 protein, V72I, from patients with HSP is functionally defective, at least when tested in an E. coli system, perhaps due to its impaired ability to form an effective chaperoning complex. It was speculated that the mutated chaperone also malfunctions in humans, and that this malfunction is responsible for some of the manifestations of HSP.

\section{CHAPERONINS OF GROUP II}

\section{McKusick-Kaufman syndrome}

Several abnormalities occur in patients with McKusickKaufman syndrome (MKS); typically, these patients display hydrometrocolpos, postaxial polydactyly, and heart disease..$^{33,34}$

The genomic alterations associated with MKS have been mapped to chromosome 20p12, where the gene MKKS is located. This gene's encoded protein is similar to a subunit of the archaeal thermosome from Thermoplasma acidophilum, which is equivalent to the eukaryotic cytosolic CCT, the archetype of group II chaperonins. It was inferred, from the similarity between MKKS and the thermosome subunit, that the former is a chaperone, part of the CCT. Two mutations were found to be responsible for MKS. ${ }^{33} \mathrm{~A}$ comparison of the crystal structure of the thermosome from T. acidophilum with a model thermosome built in the computer using the mutant MKKS proteins instead of the archaeal counterparts, was performed. The comparison revealed that the MKS mutations would disrupt the thermosome structure, which depends on the correct assembly of, and interactions among, the subunits. Thus, the chaperoning functions of the CCT would be seriously impaired if a mutated subunit of the type found in patients with MKS became incorporated in the chaperonin complex. That this is the operative mechanism awaits experimental demonstration. Nonetheless, it was suggested that failure of the CCT during development and growth would lead to protein misfolding, aggregation, and precipitation in many tissues, for example those in the limbs, heart, and reproductive organs, thereby producing the abnormalities observed in patients with MKS. ${ }^{33}$ This is an interesting suggestion that should stimulate further research into elucidation of the pathogenetic mechanisms causing the various manifestations of MKS. In this regard, it should be mentioned that a 143 base-pair deletion in the gene encoding the CCT gamma subunit of zebrafish has been implicated in developmental defects in this model organism. ${ }^{35}$

\section{Bardet-Biedl syndrome}

Bardet-Biedl syndrome (BBS) is characterized by a series of abnormalities, some similar to those observed in MKS: retinitis pigmentosa, obesity, polydactyly, learning disability, hypogonadism, and renal anomalies, ${ }^{36,37}$ with linkages to eight or more loci. ${ }^{38-43}$ The genes implicated are involved in a variety of functions. In this review, we focus on one of these genes, MKKS (locus BBS6), which is associated with some forms of the condition: it encodes a protein resembling a CCT subunit and was found to be mutated in four cases of BBS. ${ }^{44}$ As explained earlier for MKS, failure of the chaperoning function of CCT due to the presence of mutant subunits would lead to protein misfolding, aggregation, and precipitation in retina, brain, and pancreas, producing some of the anomalies typically seen in BBS. Here again, further research is needed to ascertain whether the wild-type protein behaves in vivo as a chaperone, as suggested by its structural features, and to assess the consequences of the mutations on this protein's functions.

\section{Hereditary sensory neuropathy}

The term hereditary sensory neuropathy (HSN) is used to designate a large and heterogeneous group of hereditary neuropathies. Among these, the most common ones are CharcotMarie-Tooth (CMT) disease (also called hereditary motor and sensory neuropathy or HMSN); and HSNs or hereditary sensory and autonomic neuropathies (HSAN). ${ }^{45}$

Animal models for these diseases are available. One of them is an autosomal, recessive, early-onset sensory neuropathy in the rat. The implicated mutation is called mutilated foot $(\mathrm{mf})$, and is characterized by ataxia, insensitivity to pain, and foot ulceration. In this animal model, it was found that the $m f$ locus contains Cct4, which encodes the CCT delta subunit, in a mutated form, in which the highly conserved cysteine- 450 is replaced by tyrosine. This would, as explained, interfere with the assembly of a competent CCT, resulting in abnormalities due to the lack of the correct mechanism for protein folding in the various tissues affected by the syndrome. Although an analogous mutation was not found in the human Cct4, the finding in the rat model should encourage research in similar directions, for patients affected with any of the HSN syndromes.

\section{CHAPERONE CO-FACTORS INVOLVED IN TUBULIN FOLDING AND MICROTUBULE BIOGENESIS}

\section{Cofactor C}

\section{$X$-linked retinitis pigmentosa}

Progressive degeneration of photoreceptor cells in the retina characterizes X-linked retinitis pigmentosa (RP or XLRP). Once begun, the degenerative process continues over 20-30 
years and may eventually result in blindness. Over 30 loci and several gene defects have been implicated in RP. Some of the mutated genes have no known function; one such is RP2, which encodes a protein of 350 amino acids. ${ }^{46}$ The N-terminal segment of RP2 has similarity with cofactor C, which in humans is one of a set of at least five chaperones (A through $\mathrm{E}$ ) involved in tubulin folding. ${ }^{46,47}$ Cofactors $\mathrm{C}$ and $\mathrm{D}$ activate tubulin GTPase (hence they are called GTPase activator proteins, or GAP). RP2, together with cofactor D, serves as the GAP for tubulin, meaning that RP2 can replace cofactor C. Although RP2 replaced cofactor C to act as GAP in conjunction with cofactor D, RP2 did not catalyze tubulin heterodimerization as cofactor $\mathrm{C}$ did.

Missense and protein-truncation mutations of $R P 2$ have been identified. The missense mutations were localized to the cofactor $\mathrm{C}$ homologous position of the RP2 gene, which might thus have impaired catalytic activities. The various mutations of $R P 2$ were tested, to determine the localizations and distributions of the respective proteins within the cell. ${ }^{46}$ The proteins were found to be either absent or abnormally distributed. It was hypothesized that lack, and/or abnormal distribution, of the RP2 protein, contributes to cell pathology. This could thus represent an example of failure by a chaperone to recruit other chaperone molecules (networking) and to thereby build a chaperoning network.

Recently, it was demonstrated that if RP2 has a mutation in arginine 118, or if cofactor $\mathrm{C}$ has a mutation in arginine 262, the tubulin-GTPase stimulatory ability of each protein is lost. ${ }^{47}$ These and other data from experiments with Saccharomyces cerevisiae indicated that RP2 and cofactor $\mathrm{C}$ have overlapping functions, in addition to other functions that are specific to each molecule. It was also shown that RP2 reacts with ADPribosylation factor-like 3-protein, when the latter protein is bound to GTP. This finding links RP2 with several other retinal proteins, which, when mutated, are also associated with RP.

\section{Cofactor E}

HRD or Sanjad-Sakati syndrome and Kenny-Caffey syndrome

HRD and Kenny-Caffey syndrome (AR-KCS), both consist of congenital hypoparathyroidism, mental retardation, facial dysmorphism, and severe impairment of growth; additionally, in AR-KCS, osteosclerosis and repeated bacterial infections occur. Mutations (deletions and truncations) in the gene $T c b E$, encoding cofactor $\mathrm{E}$, were found in both disorders. ${ }^{48}$ Because cofactor $\mathrm{E}$ is involved in cytoskeletal biogenesis, the cytoskeleton was examined in diseased cells, in efforts to determine pathogenetic mechanisms. Fibroblasts and lymphoid cells from affected individuals had a density of microtubules at the microtubule-organizing center that was lower than the density in their normal counterparts. Also, the microtubule polarity was altered in the patients' cells. These finding prompted the suggestion that E-gene mutations that curtail the chaperoning capacity of its protein product (due, for example, to impairment of its networking ability, which would interfere with its interaction with the other cofactors, A through D) can cause HRD.

\section{Progressive motor neuronopathy}

Mice homozygous for the pmn mutation in chromosome 13 suffer a progressive caudocranial degeneration of motor axons starting at 2 weeks after birth, ending in death 2-4 weeks later. ${ }^{49}$ These animals serve as a model for studies pertinent to the autosomal recessive proximal spinal muscular atrophy (SPM) of children. A missense mutation in the gene $T b c E$, encoding cofactor $\mathrm{E}$ in mice, has been implicated as a cause of progressive motor neuronopathy (PMN). ${ }^{49,50}$ Examination of the sciatic and phrenic nerves of affected mice, by electron microscopy, showed a scarcity of microtubules. This anomaly could be corrected by transgenic complementation with a wild-type gene. ${ }^{49}$ The conclusion was that the $T b c E$ gene, and consequently its protein product, cofactor $\mathrm{E}$, play a key role in microtubule biogenesis and stability in motor neurons. Most importantly, when cofactor $\mathrm{E}$ is altered, motor neuron disease ensues. Gene expression studies, gene mappings, and sequence analyses all suggested that the mouse $T b c E$ gene in chromosome 13 is the ortholog of the human TBCE gene in chromosome 1q42.3. These data, taken together with those from studies of HRD and AR-KCS patients discussed earlier, support the involvement of human TBCE in motor neuron disease. The intrinsic molecular mechanisms involved in the pathogenesis of HRD and AR-KCS are not yet understood, but a failure of cofactor E networking abilities (as described for HRD) is one possibility to consider, as a working hypothesis, in research aiming at identifying pathogenetic factors and molecular targets for therapeutics.

\section{SMALL Hsp}

\section{Hsp27}

Williams syndrome

Deletion of the gene encoding the sHsp Hsp27 was found in patients with Williams syndrome (WS). ${ }^{51}$ The gene is located in chromosome $7 \mathrm{q} 11.23$, telomeric to the typical WS deletion region. Three patients with the longer deletion regions, including the $h s p 27$ gene, showed the classical WS features (mental retardation, facial dysmorphism, elastin arteriopathy, and the characteristic cognitive profile and personality), but mental retardation was more severe than in the patients with deletions that did not include $h s p 27$.

Hsp27, the product of $h s p 27$, is an actin-binding chaperone involved in actin polymerization and formation of the cytoskeleton, and it is structurally and functionally related to the alpha-crystallins. ${ }^{51,52}$ The key role of Hsp27 in the biogenesis and maintenance of the microfilament network suggests that its absence, or functional failure, will affect those aspects of cell and tissue physiology that depend on the cytoskeleton. At least some of the manifestations of the WS can be attributed to cytoskeletal abnormalities during postnatal development and 
growth. The exact functional defect of the Hsp27 molecule that contributes to pathogenesis has not been characterized.

\section{Charcot-Marie-Tooth disease and distal hereditary motor neuropathy}

Two types of Charcot-Marie-Tooth (CMT) disease have been identified, demyelinating (CMT1) and axonal (CMT2), both characterized by peripheral nerve degeneration. ${ }^{53,54} \mathrm{At}$ least eight loci and five genes have been implicated in the causation of CMT2, which in fact constitutes a clinically and genetic heterogeneous group of disorders, with onset in teenagers and young adults. One of the genes involved, HSPB1, which encodes Hsp27, has been found with a missense mutation in a group of affected individuals. ${ }^{53}$ Other mutations in HSPB1 were found in four families with distal hereditary motor neuropathy (distal HMN) and in one case of CMT disease..$^{53}$ Transfection of mutated HSPB1 into neuronal cells resulted in impairment of the viability of these cells as compared with neuronal cells transfected with the wild-type gene.

The type of malfunction of the product of the mutated chaperone gene and the mechanism by which this malfunction contributes to the generation of the abnormalities observed in CMT disease remain to be investigated. In this regard, some pathogenetic pathways may be hypothesized if we consider the number of interactions that normally occur between sHsp and various cellular structures, such as neurofilaments and the cytoskeleton. No doubt, elucidation of what is wrong with the chaperone itself, and how this deficiency affects cellular functions, will not only shed light on pathogenesis but also will guide the development of means for disease prevention and treatment.

\section{Crystallins}

Alpha-crystallins are members of a large family within the sHsp group, and they have chaperoning abilities. ${ }^{52,55-59} \mathrm{~A}$ distinctive structural feature of these sHsp is a conserved sequence toward the middle of the molecule, about 80 amino acids in length, termed the alpha-crystallin domain. ${ }^{60}$ Usually, this domain is flanked by a nonconserved $\mathrm{N}$-terminal segment of variable length (depending on the organism), and by a short, C-terminal tail.

Most of our knowledge on alpha-crystallins stems from studies of those present in the eye lens, and it has been known for some time that the lenticular alpha-A- and alpha-B-crystallins abate protein aggregation-precipitation and the development of cataracts. ${ }^{61}$ It is important to bear mind, however, that alpha-crystallins are widespread in nature, being present in all three domains of life: archaea and bacteria (both prokaryotes) and eucarya (eukaryotes) ${ }^{59}$; in the latter organisms, they are present not only in the eye lens, but also in other tissues. ${ }^{62}$

An important characteristic of alpha-crystallins is their ability to form homo-oligomeric complexes, a property apparently dependent on the alpha-crystallin domain, and directly related to chaperoning functions. ${ }^{55}$ Thus, it can be expected that mu- tations affecting this domain will interfere both with oligomerization capability and with function.

\section{Cataracts}

The presence in the eye's lens of misfolded proteins, including crystallins, is a feature that characterizes some forms of cataracts. The association of cataracts with mutations in the crystallin genes, leading to protein misfolding, has been reported on several occasions. ${ }^{61,63-66}$ The implicated, mutated crystallin genes include $C R Y A A$ (alpha-A-crystallin), ${ }^{63} C R Y A B$ (alpha-B-crystallin), ${ }^{67,68}$ CRYBB2 (beta-B-crystallin), ${ }^{69,70}$ and CRYGC (gamma-C-crystallin).66,71 For example, a missense mutation in the human alpha-A-crystallin gene CRYAA was reported to accompany autosomal dominant congenital cataracts (ADCC) in one family. ${ }^{63}$

In another study, it was found that progressive juvenileonset punctate cataracts were caused by a mutation in the gamma-D-crystallin gene. ${ }^{72}$ The investigation focused on three generations of a family with hereditary progressive cataracts, transmitted as a fully penetrant dominant trait. In these patients, the lenses were clear at birth but, as the children grew, the lenses became increasingly opaque, and cataracts became detectable at around 2.5 years of age.

In another case, a 5-year old boy with congenital cataracts, a unique feature was observed: deposition of birefringent crystal-like inclusions in the lens. ${ }^{73}$ The inclusions were composed of the crystal-forming protein gamma-D-crystallin (CRYGD) lacking the $\mathrm{N}$-terminal methionine.

Experimentally, in mice, it was demonstrated that mutant gamma-crystallins can form aggregates in the nuclei of the primary-lens fiber cells. ${ }^{65}$ This potential of the mutant crystallins to form precipitates can contribute to lens opacity instead of, or in addition to, the precipitate-forming abilities of other, abnormal, proteins with a tendency to misfold.

Here again, the question of exactly what is wrong, in functional terms, with the lenticular chaperone (i.e., the alphacrystallin) deserves exploration, in the context of what is known about chaperones and their domains and interactions, and what we would predict to be the consequences of mutations.

In a recent study, the interaction between alpha-A- and gamma-C-crystallins was investigated, in order to elucidate the mechanism responsible for cataract formation when gammaC-crystallin is mutated. ${ }^{74} \mathrm{~A}$ mutation, T5P, is associated with Coppock-like cataracts, an example of autosomal, dominant congenital cataracts. ${ }^{66,71}$ It is not yet established why the wildtype alpha-A-crystallin (which is known to possess chaperoning capacity and which is present in the cells of the patient with this type of cataracts), cannot prevent the aggregation-precipitation of the mutant protein T5P gamma-C-crystallin (which because of its mutation tends to aggregate and precipitate). The results indicated that a decrease in the interactions of the mutant T5P with other crystallins is probably the reason why this protein remains unassisted by the chaperones and falls prey to its mutation-related tendency to aggregate and precipitate. ${ }^{74}$ 
A known crystallin mutant, alpha-A-crystallin R116C, is the result of a missense mutation in which arginine 116 is changed to cysteine. This mutation is involved in cataracts in the elderly. The stability of the quaternary structure of the alpha-Acrystallin R116C mutant was investigated, along with this mutated protein's chaperoning activity, its subunit-exchange capability, and its membrane association abilities. ${ }^{75}$ The mutant-protein complexes became highly polydisperse at $37^{\circ} \mathrm{C}$. Under these conditions, the chaperoning activity was four times lower than that of the wild-type complexes. The same trend was observed when the ability for subunit exchange was tested: the mutant was less efficient than the wild-type complex. It was speculated that these impairments in the mutant molecules and their complexes must have an impact in vivo, for several reasons: (1) the wild-type proteins, WT-alpha-Acrystallin and WT-alpha-B-crystallin, have the ability to suppress stress-induced protein aggregation, ${ }^{55}$ suggesting that these proteins do play a role in the maintenance of lens transparency; (2) the two subunits readily exchange between soluble alpha-crystallin complexes in a time- and temperature-dependent manner; (3) alpha-crystallin endows the lens with its refractive and transparency qualities via short-range molecular interactions and ordering; and (4) alpha-crystallin binds intermediate filaments and the plasma membrane. Furthermore, it is known that the amount of soluble alpha-crystallin in the cytosol of eye lens fiber cells declines with progression of both senescence and of cataracts in the aged (see references in Horwit $^{55}$ ). All of these pieces of information converge to suggest that the quantity of correctly folded alpha-crystallin available to bind partially denatured proteins (damaged by the ageing process via oxidation, deamidation, etc.) decreases during senescence. This decrease in the crystallin's chaperoning ability would lead to progressive accumulation of protein aggregates, with ensuing precipitation and formation of light-scattering inclusions in the lens.

\section{Desmin-related myopathy}

Typical of desmin-related myopathy (DRM) are desmin aggregates in skeletal and cardiac muscle. ${ }^{67}$ The various DRM syndromes all share several characteristics: they appear in the adult as neuromuscular disorders, with muscle weakness first in the limbs and then progressing to the neck, pharynx, and trunk. ${ }^{76}$ Mutations in the desmin gene have been implicated in pathogenesis. ${ }^{77}$ Another gene affected (mutation R120G) is named $C R Y A B$; it encodes alpha-B-crystallin and maps to chromosome 11q21-23.67

The product of the defective gene R120G showed decreased beta-sheet secondary structure, with reduction, or lackdepending on the substrate used in the assay-of chaperone activity in vitro. ${ }^{78}$ Alterations in secondary structure may impair one or more of the functions and interactions of chaperone molecules, and thus become a pathogenetic factor.

For elucidation of the pathogenesis of DRM associated with the mutation R120G, experiments were performed using primary cultures of muscle tissue from patients and normal controls. ${ }^{79}$ The glucocorticoid hormone dexamethasone induced expression of the alpha-B-crystallin and $h s p 27$ genes in normal cells, which were thus made resistant to the effects of heat and oxidative stresses. In contrast, these protective abilities were considerably impaired in DRM cells, correlating with the reduced expression of both chaperone genes.

Recently, an investigation was performed to determine whether the R120G mutation has an effect on the accumulation of desmin aggregates inside cells. ${ }^{80} \mathrm{R} 120 \mathrm{G}$ had a decreased capability to reduce aggregate accumulation, as compared with the wild-type protein. Aggregate formation and accumulation were prevented by wild-type alpha-B-crystallin and Hsp27, and these two normal proteins co-oligomerized with the defective R120G molecule. Likewise, Hsp70 together with Hdj-1 [of the Hsp40(DnaJ) family] also reduced the cell load in aggregates. It was suggested that the aggregates form in DRM because the R120G protein cannot fold correctly due to its mutation, and that misfolding, aggregation, and precipitation might be preventable, or at least slowed down considerably, by the chaperoning action of alpha-B-crystallin, either alone or in conjunction with other chaperones.

\section{Hsp22}

\section{Distal motor neuropathy}

Distal motor neuropathy (DMN) comprises a genetically heterogeneous group of conditions, in which several loci and genes have been found to be abnormal (see references in Irobi et al. ${ }^{81}$ ). Two mutations (K141N and K141E) were recently identified in the gene HSPB8 (HSP22) in cases of DMN type II. ${ }^{81}$ The mutated amino acid (lysine) is located in the central alpha-crystallin domain, is highly conserved, and is key to the functional efficiency of the sHsp alpha-A-crystallin: mutations at this position are known to cause various disorders (see "Cataracts" and "Desmin-related myopathy").

\section{PEPTIDYL-PROLYL CIS-TRANS ISOMERASE (PPIase)}

\section{Leber congenital amaurosis}

Leber congenital amaurosis (LCA) is a severe and inheritable form of retinopathy, manifested at birth as a serious vision impairment, or blindness. ${ }^{82,83} \mathrm{~A}$ number of loci and mutated genes have been implicated in LCA. ${ }^{83,84}$ One of these genes, AIPL1 (aryl-hydrocarbon receptor-interacting protein-like 1), is involved in LCA4. ${ }^{83,85,86}$ The protein product of AIPL1, AIPL1, has 384 amino acids and three tetratricopeptide repeats (TPR), suggesting its involvement in nuclear transport and/or protein-protein interactions, such as those observed during the formation and function of chaperone complexes. The gene was mutated in LCA patients of the original LCA4 family.

The amino-acid sequence of AIPL1 is $49 \%$ identical to that of the human aryl-hydrocarbon receptor-interacting protein (AIP), a member of the FK506-binding protein (FKBP) family with chaperone functions; all of these proteins contain TPR. ${ }^{82,86,87}$ Comparative analyses of primary structures revealed that all mammalian AIPs are conserved and are related to the FKBP group of chaperones. ${ }^{85}$ The FKBP chaperones 
function in steroid receptor signaling, heat-shock response, and immunosuppression. Hence, it was hypothesized that AIPL1 is also a molecular chaperone with functions similar to those of the FKBPs. Mutations could alter some of the functions and interactions of AIPL1 in a manner that can be inferred from what is known about the interactions of chaperones.

A specific and strong interaction of AIPL1 with farnesylated proteins has been demonstrated; this interaction was impaired by mutations. ${ }^{88}$ Farnesylation is a posttranslational modification (prenylation) that occurs in the C-termini of a variety of proteins, including those in retinal cells essential for vision. Thus, it was suggested that one of the causes of LCA is the failure of AIPL1 to assist in the farnesylation of retinal proteins when AIPL1 has mutations that interfere with its farnesylation-assistance function. ${ }^{88}$

\section{OTHER CANDIDATES}

\section{Proteins with DnaJ-Hsp90 markers}

\section{Autosomal recessive spastic ataxia of Charlevoix-Saguenay}

The gene responsible for Autosomal recessive spastic ataxia of Charlevoix-Saguenay (ARSACS or SACS) has been mapped to chromosome 13q11. ${ }^{89}$ It encodes sacsin in a single, very long exon encompassing nearly 13,000 base pairs. A protein similar to sacsin is also found in mice and Arabidopsis thaliana. Sacsin would possess on its C-terminal half a J domain [found in many proteins such as the chaperones of the Hsp40(DnaJ) group], and an $\mathrm{N}$-terminal domain similar to the N-terminal domain of $\mathrm{Hsp} 90^{89}$ but we could confirm the latter (unpublished). The occurrence in sacsin of chaperone markers would suggest that sacsin is a chaperone. If indeed sacsin is a chaperone, then mutations affecting domains involved in the interactions and functions of a chaperone could be pathogenic. Demonstration of chaperoning functions for sacsin should be a very attractive line of research in the quest to elucidate the molecular mechanisms responsible for the manifestation of ARSACS.

Recently, new mutations of the SACS gene were reported. ${ }^{90-92}$ Any of these mutations could have a damaging effect on sacsin's chaperoning functions (although this awaits experimental confirmation), and could thus account for the anomalies seen in ARSACS.

\section{Alpha-synuclein: An emerging chaperone?}

\section{Parkinson's disease}

Alpha-, beta-, and gamma-synucleins are members of a family of related proteins that display chaperoning activities in vitro. ${ }^{93}$ Their physiologic roles in vivo have not yet been fully elucidated. Alpha-synuclein is a presynaptic protein, associated with several neurodegenerative disorders, ${ }^{3,94}$ whose parent gene is mutated in some forms of Parkinson disease. ${ }^{95,96} \mathrm{It}$ was recently found that the chaperone alpha-B-crystallin (a sHsp) inhibits, in vitro, the formation of fibrils by wild-type alpha-synucleins and by the two mutant alpha-synucleins implicated in early-onset Parkinson disease. ${ }^{97}$ Inhibition of fibril- lization was accompanied by formation of large, irregular, aggregates containing alpha-B-crystallin and alpha-synuclein. These amorphous aggregates would presumably be less stable and more easily disaggregated by specialized chaperones than are the fibrils formed by alpha-synuclein in the absence of alpha-B-crystallin. The generation of these amorphous aggregates would preempt the formation of stable, deleterious, intracellular amyloid inclusions, such as the Lewy bodies seen in Parkinson disease. It was also observed that the two mutant alpha-synucleins typical of early-onset Parkinson disease had reduced chaperoning activity in vitro: they were less efficient than was the wild-type molecule in minimizing the aggregation of two test proteins that had been partially denatured for the purpose of the assay.

Another interesting finding pertains to the degradation pathway of alpha-synuclein, which involves this protein's translocation into lysosomes and which is assisted by chaperones. ${ }^{98}$ The alpha-synuclein mutants A53T and A30P, which are part of the pathogenic build-up of Parkinson disease, did not complete the translocation route: they remained stuck on the lysosomal membrane. Thus, we may infer that accumulation of alpha-synuclein in the Lewy bodies is due to the inability of the cell to degrade the mutant molecules. Furthermore, it was found that the two mutants not only did not translocate into the lysosome, but they also interfered with the translocation of other protein destined for transport to this organelle for digestion. This would constitute one example of chaperone failure due not to a defective chaperone but rather to a structural abnormality in the substrate that cannot be recognized/ assisted by the chaperone.

If alpha-synuclein is definitively shown to be a chaperone, as some of the results mentioned suggest, Parkinson disease will have to be considered a chaperonepathy. This shift in perspective would not only suggest new avenues for developing novel therapeutic strategies and means, but it would also dramatically broaden interest in chaperonepathies.

\section{Mitochondrial protein-specific chaperones}

\section{Mitochondrial diseases}

This term is usually applied to disorders of the respiratory chain in mitochondria. ${ }^{99}$ A number of proteins in the mitochondria are involved in the respiratory pathway. Some of these proteins are encoded in genes located in the mitochondrial DNA, whereas others are coded by genes in the nuclear DNA, and mutations in these genes can cause disease. ${ }^{99}$ The specific roles of all these proteins are still under investigation, but it is already clear that some form assemblages to exercise their functions in the respiratory pathway whereas others assist in the assembly process. The latter "assembly factors" may be regarded as chaperones that, when altered by mutations, would fall within the genetic chaperonepathy class of disorders.

\section{CONCLUSIONS AND PERSPECTIVES}

At least 15 pathologic conditions have been reported in which a gene encoding a chaperone, or a molecule sharing 
structural features with known chaperones, is mutated or absent. These conditions, which can be classified as genetic chaperonepathies, are characterized by abnormalities in the nervous, muscular, or other tissues, and they may be considered inborn errors of development, a term coined to encompass a variety of genetically determined developmental disorders. ${ }^{100}$ The precise nature of the chaperone malfunction and the exact role of the defective chaperone in the development of the clinical and anatomic abnormalities are still under investigation. However, the types of chaperone malfunctions due to mutations, as well as the impact of these malfunctions on protein biogenesis and other cellular processes in vivo, may be inferred from the known interactions and functions of chaperones. It is likely that at least a subset of the pathologic manifestations characteristic of those syndromes in which a chaperone gene is mutated are due to malfunction of the mutant chaperone protein. Studies on the degree and type (e.g., substrate binding strength and specificity) of mutant chaperone malfunction and the impact of this malfunction upon development of various tissues and organs promise to be rewarding. Also, considering the data available, the situation is ripe now to undertake a search for new genetic chaperonepathies. It is likely that we may uncover new pathologies and expand our knowledge of conditions, such as those discussed in this article, whose pathogenetic mechanisms are still incompletely understood. These goals can be achieved by reexamining samples from patients already identified but that were not tested to fully ascertain if they carried a chaperonepathy or to elucidate its molecular mechanism, and by studying new potential carriers of this abnormality. In parallel, it will be necessary to conduct similar studies using experimental models and the techniques applied to other genetic disorders to map chromosomal abnormalities, unveil genetic polymorphisms, detect gene mutations, compare genomes focusing on chaperone genes (chaperonomics), and analyze gene sequences and find their matches in genomic databases. In addition, the mutated genes and their protein products should be tested in vivo (e.g., gene complementation) and in vitro (e.g., determination of chaperoning ability with regard to a denatured test polypeptide) to establish their contributions to the chaperoning-protein quality control mechanisms, and to measure the extent of impairment of these mechanisms when they are mutated. This is critical because there is overlap among chaperoning systems that have probably been conserved during evolution to provide compensatory mechanisms in case one of the components fails.

\section{ACKNOWLEDGMENTS}

T.M. Grippo was partially supported by a fellowship from the "Consultorio de Neurologia Infantil." We thank T. GarciaCollins for her help with the comparative and phylogenetic analyses of human genes.

\section{References}

1. Kopito RR. Aggresomes, inclusion bodies and protein aggregation. Trends Cell Biol 2000;10:524-530.

2. Dobson CM. Protein folding and misfolding. Nature 2003;426:884-890.
3. Ross CP, Poirier MA. Protein aggregation and neurodegenerative disease. Nat Med 2004;10(suppl):S10-S17.

4. Vidal R, Delisle MB, Ghetti B. Neurodegeneration caused by proteins with an aberrant carboxyl-terminus. J Neuropathol Exp Neurol 2004;3:787-800.

5. Barral JM, Broadley SA, Schaffar G, Hartl FU. Roles of molecular chaperones in protein misfolding diseases. Semin Cell Dev Biol 2004;15:17-29.

6. Ellis RJ, Hartl FU. Principles of protein folding in the cellular environment. Curr Op Struc Biol 1999;9:102-110.

7. Bukau B, Deuerling E, Pfund C, Craig EA. Getting newly synthesized proteins into shape. Cell 2000;101:119-122.

8. Hartl FU, Hayer-Hartl M. Molecular chaperones in the cytosol: From nascent chain to folded protein. Science 2002;295:1852-1858.

9. Truscott KN, Brandner K, Pfanner N. Mechanism of protein import into mitochondria. Curr Biol 2003;13:R326-R337.

10. Lum R, Tkach JM, Vierling E, Glover JR. Evidence for an unfolding/threading mechanism for protein disaggregation by Saccharomyces cerevisiae Hsp104. J Biol Chem 2004;279:29139-29146.

11. Maurizi MR, Xia D. Protein binding and disruption by $\mathrm{Clp} / \mathrm{Hsp} 100$ chaperones. Structure 2004;12:175-183.

12. Schlee S, Beinker P, Akhrymuk A, Reinstein J. A chaperone network for the resolution of protein aggregates: Direct interaction of $\mathrm{ClpB}$ and DnaK. J Mol Biol 2004;336:275-285.

13. Hoehfeld J, Cyr DM, Patterson C. From the cradle to the grave: Molecular chaperones may choose between folding and degradation. EMBO Rep 2001;21:885890.

14. Glickman $\mathrm{MH}$, Ciechanover A. The ubiquitin-proteasome proteolytic pathway: Destruction for the sake of construction. Physiol Rev 2002;82:373-428.

15. Macario AJL, Conway de Macario E. Molecular chaperones and age-related degenerative disorders. Adv Cell Aging Gerontol 2001;7:131-162.

16. Sghaier H, Ai TL, Horiike T, Shinozawa T. Molecular chaperones: proposal of a systematic computer-oriented nomenclature and construction of a centralized database. In Silico Biol 2004;4:01-19.

17. Caplan AJ. What is a co-chaperone. Cell Stress Chap 2003;8:105-107.

18. Chapple JP, Grayson C, Hardcastle AJ, Saliba RS, van der Spuy J, Cheetham ME. Unfolding retinal dystrophies: A role for molecular chaperones? Trends $\mathrm{Mol} \mathrm{Med}$ 2001;7:414-421.

19. Csermely P. Chaperone overload is a possible contributor to 'civilization disease.' Trends Genet 2001;17:701-704.

20. Slavotinek AM, Biesecker LG. Unfolding the role of chaperones and chaperonins in human disease. Trends Genet 2001;17:528-535.

21. Soti C, Csermely P. Chaperones and aging: role in neurodegeneration and in other civilizational diseases. Neurochem Intl 2002;41:383-389.

22. Soti C, Csermely P. Aging and molecular chaperones. Exp Gerontol 2003;38:10371040

23. Macario AJL, Conway de Macario E. Sick chaperones and ageing: A perspective. Ageing Res Rev 2002;1:295-311.

24. Macario AJL, Conway de Macario E. Stress and molecular chaperones in disease Intl J Clin Lab Res (currently Clin Exp Med) 2000;30:49-66.

25. Snoeckx LHEH, Cornelussen RN, van Nieuwenhoven FA, Reneman RS, van der Vusse GJ. Heat shock proteins and cardiovascular pathophysiology. Physiol Rev 2001;81:1461-1497.

26. Verbeke P, Fonager J, Clark BFC, Rattan SIS. Heat shock response and ageing: Mechanisms and applications. Cell Biol Intl 2001;25:845-857.

27. Hay DG, Sathasivam K, Tobaben S, Stahl B, Marber M, Mestril R et al. Progressive decrease in chaperone protein levels in a mouse model of Huntington's disease and induction of stress proteins as a therapeutic approach. Hum Mol Gen 2004;13: $1389-1405$

28. Verhoef LGGC, Lindsten K, Masucci M, Dantuna NP. Aggregate formation inhibits proteasomal degradation of polyglutamine proteins. Hum Mol Genet 2002;11: 2689-2700.

29. Ciechanover A, Brundin P. The ubiquitin proteasome system in neurodegenerative diseases: Sometimes the chicken, sometimes the egg. Neuron 2003;40:427-446.

30. Li Z, Arnaud L, Rockwell P, Figueiredo-Pereira ME. A single amino acid substitution in a proteasome subunit triggers aggregation of ubiquitinated proteins in stressed neuronal cells. J Neurochem 2004;90:19-28.

31. Hansen JJ, Bross P, Westergaard M, Nielsen M, Eiberg H, Borglum AD et al Genomic structure of the human mitochondrial chaperonin genes: HSP60 and HSP10 are localised head to head on chromosome 2 separated by a bidirectional promoter. Hum Genet 2003;112:71-77.

32. Hansen JJ, Durr A, Cournu-Rebeix I, Georgopoulos C, Ang D, Nielsen MN et al Hereditary spastic paraplegia SPG13 is associated with a mutation in the gene encoding the mitochondrial chaperonin Hsp60. Am J Hum Genet 2002;70:13281332 
33. Stone DL, Slavotinek A, Bouffard GG, Banerjee-Basu S, Baxevanis AD, Barr M et al. Mutations of a gene encoding a putative chaperonin causes McKusick-Kaufman syndrome. Nat Genet 2000;25:79-82.

34. Slavotinek AM, Dutra A, Kpodzo D, Pak E, Nakane T, Turner J et al. A female with complete lack of Müllerian fusion, postaxial polydactyly, and tetralogy of fallot: Genetic heterogeneity of McKusick-Kaufman syndrome or a unique syndrome? Am J Med Genet 2004;129A:69-72.

35. Matsuda N, Mishina N. Identification of chaperonin CCT gamma subunit as a determinant of retinotectal development by whole-genome subtraction cloning from zebrafish no tectal neuron mutant. Development 2004;131:1913-1925.

36. Katsanis N, Beales PL, Woods MO, Lewis RA, Green JS, Parfrey PS et al. Mutations in MKKS cause obesity, retinal dystrophy and renal malformation associated with Bardet-Biedl syndrome. Nat Genet 2000;26:67-70.

37. Katsanis N, Lupski JR, Beales PL. Exploring the molecular basis of Bardet-Biedl syndrome. Hum Mol Genet 2001;10:2293-2299.

38. Ansley SJ, Badano JL, Blacque OE, Hill J, Hoskins BE, Leitch C et al. Basal body dysfunction is a likely cause of pleiotropic Bardet-Biedl syndrome. Nature 2003; 425:628-633.

39. Badano JL, Kim JC, Hoskins BE, Lewis RA, Ansley SJ, Cutler DJ et al. Heterozygous mutations in BBS1, BBS2 and BBS6 have a potential epistatic effect on Bardet-Bied patients with two mutations at a second BBS locus Hum Mol Gen 2003;12:16511659.

40. Fan Y, Esmail MA, Ansley SJ, Blacque OE, Boroevich K, Ross AJ, Moore SJ et al. Mutations in a member of the Ras superfamily of small GTP-binding proteins causes Bardet-Biedl syndrome. Nat Genet 2004;36:989-993.

41. Kim JC, Badano JL, Sibold S, Esmail MA, Hill J, Hoskins B et al. The Bardet-Biedl protein BBS4 targets cargo to the pericentriolar region and is required for microtubule anchoring and cell cycle progression. Nat Genet 2004;36:462-470.

42. Mykytyn K, Sheffield VC. Establishing a connection between cilia and Bardet-Biedl syndrome. Trends Mol Med 2004;10:106-109.

43. Ye X, Dai J, Fang W, Jin W, Guo Y, Song J et al. Cloning and characterization of a splice variant of human Bardet-Biedl syndrome 4 gene (BBS4). DNA Seq 2004;15: 213-218.

44. Slavotinek AM, Stone EM, Mykytyn K, Heckenlively JR, Green JS, Heon E, Musarella MA et al. Mutations in MKKS cause Bardet-Biedl syndrome. Nat Genet 2000; 26:15-16.

45. Lee MJ, Stephenson DA, Groves MJ, Sweeney MG, Davis MB, An SF et al. Hereditary sensory neuropathy is caused by a mutation in the delta subunit of the cytosolic chaperonin-containing t-complex peptide-1 (Cct4) gene. Hum Mol Genet 2003;12:1917-1925.

46. Schwahn U, Paland N, Techritz S, Lenzner S, Berger W. Mutations in the X-linked RP2 gene cause intracellular misrouting and loss of the protein. Hum Mol Genet 2001;10:1177-1183.

47. Bartolini F, Bhamidipatis A, Thomas S, Schwahn U, Lewis SA, Cowan NJ. Functional overlap between retinitis pigmentosa 2 protein and the tubulin-specific chaperone cofactor C. J Biol Chem 2002;277:14629-14634.

48. Parvari R. and the HRD/Autosomal Recessive Kenny-Caffey Syndrome Consortium. Mutation of TBCE causes hypoparathyroidim retardation-dysmorphism and autosomal recessive Kenny-Caffey syndrome. Nat Genet 2002;32:448-452.

49. Martin N, Jaubert J, Gounon P, Salido E, Haase G, Szatanik M et al. A missense mutation in Tbce causes progressive motor neuronopathy in mice. Nat Genet 2002; 32:443-447.

50. Boemmel H, Xie G, Rossoll W, Wiese S, Jablonka S, Boehm T et al. Missense mutation in the tubulin-specific chaperone $E$ (Tcbe) gene in the mouse mutant progressive motor neuronophathy, a model of human motoneuron disease. J Cell Biol 2002;159:563-569.

51. Stock AD, Spallone PA, Dennis TR, Netski D, Morris CA, Mervis CB et al. Heat shock protein 27 gene: Chromosomal and molecular location and relationship to Williams syndrome. Am J Med Genet 2003;120A:320-325.

52. Kappe G, Franck E, Verschuure P, Boelens WC, Leunissen JAM, de Jong WW. The human genome encodes 10 alpha-crystallin-related small heat shock proteins: HspB1-10. Cell Stress Chaper 2003;8:53-61.

53. Evgrafov OV, Mersiyanova I, Irobi J, van Den Bosch L, Dierick I, Leung CL, et al. Mutant small heat-shock protein 27 causes axonal Charcot-Marie-Tooth disease and distal hereditary motor neuropathy. Nat Genet 2004;36:602-606.

54. Tang B, Luo W, Xia K, Xiao J, Jiang H, Shen L et al. A new locus for autosomal dominant Charcot-Marie-Tooth disease type 2 (CMT2L) maps to chromosome 12q24. Hum Genet 2004;114:527-533.

55. Horwitz J. Alpha-crystallin can function as a molecular chaperone. Proc Natl Acad Sci U S A USA 1992;89:10449-10453.

56. Jakob U, Gaestel M, Engel K, Buchner J. Small heat shock protenis are molecular chaperones. J Biol Chem 1993;268:1517-1520.

57. Andley UP, Mathur S, Griest TA, Petrash JM. Cloning, expression, and chaperonelike activity of human alpha-crystallin. J Biol Chem 1996;271:31973-31980.
58. Cobb BA, Petrash JM. Alpha-crystallin chaperone-like activity and membrane binding in age-related cataracts. Biochemistry 2002;41:483-490.

59. Narberhaus F. Alpha-crystallin-type heat shock proteins: Socializing minichaperones in the context of a multichaperone network. Microbiol Mol Biol Rev 2002;66: $64-93$

60. Caspers GJ, Leunissen JAM, de Jong WW. The expanding small heat-shock protein family, and structure predictions of the conserved 'alpha-crystallin domain' J Mol Evol 1995;40:238-248.

61. Brady JP, Garland D, Duglas-Tabor Y, Robinson WGJ, Groome A, Wawrousek EF. Targeted disruption of the mouse alpha-A-crystallin gene induces cataract and cytoplasmic inclusion bodies containing the small heat shock protein alpha-Bcrystallin. Proc Natl Acad Sci USA 1997;94:884-889.

62. Arrigo AP, Landry J Expression and function of the low molecular weight heatshock proteins. In: Morimoto RI, Tissieres A, Georgopoulos C, eds. The biology of heat shock proteins and molecular chaperones. Cold Spring Harbor, NY: Cold Spring Harbor Press, 1994:335-373

63. Litt M, Kramer P, LaMorticella DM, Murphey W, Lovrien EW, Weleber RG. Autosomal dominant congenital cataract associated with a missense mutation in the human alpha crystallin gene CRYAA. Hum Mol Genet 1998;7:471-474.

64. Trent JM, Smith L, Brownstein MJ. Progressive juvenile-onset punctate cataracts caused by mutations of the gammaD-crystallin gene. Proc Natl Acad Sci USA 1999; 96:1008-1012.

65. Sandilands A, Hutcheson AM, Long HA, Prescott AR, Vrensen G, Loster J et al Altered aggregation properties of mutant gamma crystallins cause inherited cataract. $E M B O J$ 2002;21:6005-6014.

66. Santhiya ST, Manohar MS, Rawlley D, Vijayalakshmi P, Namperumalsamy P, Gopinath PM et al. Novel mutation in the gamma-crystallin genes cause autosomal dominant congenital cataracts. J Med Genet 2002;39:352-358.

67. Vicart P, Caron A, Guicheney P, Li Z, Prevost MC, Faure A et al. A missense mutation in the alpha-B-crystallin chaperone gene causes a desmin-related myopathy. Nat Genet 1998;20:92-95.

68. Berry V, Francis P, Reddy MA, Collyer D, Vithana E, MacKay I et al. Alpha-Bcrystallin gene $(C R Y A B)$ mutation causes dominant congenital posterior polar cataract in humans. Am J Hum Genet 2001;69:1141-1145.

69. Litt M, Carrero-Valenzuela R, LaMorticella DM, Schultz DW, Mitchell TN, Kramer P et al. Autosomal dominant cerulean cataract is associated with a chain termination mutation in the human beta-crystallin gene CRYBB2. Hum Mol Genet 1997;6:665-668.

70. Gill D, Klose R, Munier FL, McFadden M, Priston M, Billingsley G et al. Genetic heterogeneity of Coppock-like cataract: A mutation in CRYBB2 on chromosome 22q11.2. Invest Ophthalmol Vis Sci 2000;41:159-165.

71. Heon E, Priston M, Schorderet DF, Billingsley GD, Girard PO, Lubsen N et al. The gamma-crystallins and human cataracts: A puzzle made clearer. Am J Hum Genet 1999;65:1261-1267.

72. Stephan DD, Gillanders E, Vanderveen D, Freas-Lutz D, Wistow G, Baxevanis AD et al. Progressive juvenile-onset punctate cataracts caused by mutations of the gamma-D-crystallin gene. Proc Natl Acad Sci USA 1999;96:1008-1012.

73. Kmoch S, Brynda J, Asfaw B, Bezouska K, Novak P, Rezacova P et al. Link between a novel human gamma-D-crystallin allele and a unique cataract phenotype explained by protein crystallography. Hum Mol Genet 2000;9:1779-1786.

74. Liang JJ-N. Interactions and chaperone function of alpha-A-crystallin with T5P gamma-C-crystallin mutant. Protein Sci 2004;13:2476-2482.

75. Cobb BA, Petrash JM. Structural and functional changes in the alpha-A-crystallin R116C mutant in hereditary cataracts. Biochemistry 2000;39:15791-15798.

76. Goudeau B, Dagvadory A, Rodrigues-Lima F, Nedellec P, Casteras-Simon M, Perret $\mathrm{E}$ et al. Structural and functional analysis of a new desmin variant causing desmin-related myopathy. Hum Mut 2001;18:388-396.

77. Goldfarb LG, Park KY, Cervenakova L, Gorokhova S, Lee HS, Vasconcelos O et al Missense mutations in desmin associated with familial cardiac and skeletal myopathy. Nat Genet 1998;19:402-403.

78. Bova MP, Yaron O, Huang Q, Ding L, Haley DA, Stewart PL et al. Mutation R120G in alpha-B-crystallin, which is linked to a desmin-related myopathy, results in an irregular structure and defective chaperone-like function. Proc Natl Acad Sci U S A USA 1999;96:6137-6142.

79. Nedellec P, Edling Y, Perret E, Fardeau M, Vicart P. Glucocorticoid treatment induces expression of small heat shock proteins in human satellite cell populations: Consequences for a desmin-related myopathy involving the R120G alpha B-crystallin mutation. Neuromuscul Disord 2002;12:457-465.

80. Chavez Zobel AT, Loranger A, Marceau N, Theriault JR, Lambert H, Landry J. Distinct chaperone mechanisms can delay the formation of aggresomes by the myopathy-causing R120G alpha-B-crystallin mutant. Hum Mol Genet 2003;12: $1609-1620$ 
81. Irobi J, van Impe K, Seeman P, Jordanova J, Dierick I, Verpoorten N et al. Hot-spot residue in small heat-shock protein 22 causes distal motor neuropathy. Nat Genet 2004;36:597-601.

82. Sohocki MM, Bowne SJ, Sullivan LS, Blackshaw S, Cepko CL, Payne AM et al. Mutations in a new photoreceptor-pineal gene on 17p cause Leber congenital amaurosis. Nat Genet 2000;24:79-83.

83. Preising MM, Heegaard S. Recent advances in early-onset severe retinal degeneration: more than just basic research? Trends Mol Med 2004;10:51-54.

84. Cremers FPC, van den Hurk JAJM, den Hollander AI. Molecular genetics of Leber's congenital amaurosis. Hum Mol Genet 2002;11:1169-1176.

85. Sohocki MM, Sullivan LS, Tirpak DL, Daiger SP. Comparative analysis of arylhydrocarbon receptor interacting protein-like 1 (Aipl1), a gene associated with inherited retinal disease in humans. Mamm Genome 2001;12:566-568.

86. van der Spuy J, Cheetham ME. Role of AIP and its homologue the blindnessassociated protein AIPL1 in regulating client protein nuclear translocation. Biochem Soc Tran 2004;32:643-645.

87. Maruyama T, Suzuki R, Furutani M. Archaeal Archaeal peptidyl prolyl cis-trans isomerases (PPIases) update 2004. Front Biosci 2004;9:1680-1700. Available at: http://www.bioscience.org/2004/v9/af/1361/fulltext.htm.

88. Ramamurthy V, Roberts M, van den Akker F, Niemi G, Reh TA, Hurley JB. AIPL1, a protein implicated in Leber's congenital amaurosis, interacts with and aids in processing of farnesylated proteins. Proc Natl Acad Sci USA 2003;100: $12630-12635$.

89. Engert JC, Berube P, Mercier J, Dore C, Lepage P, Ge B et al. ARSACS, a spastic ataxia common in Northeastern Quebec, is caused by mutations in a new gene encoding an 11.5-kb ORF. Nat Genet 2000;24:120-125.

90. Criscuolo C, Banfi S, Orio M, Gasparini P, Monticelli A, Scarano V et al. A novel mutation in SACS gene in a family from southern Italy. Neurology 2004;62:100102.
91. Grieco GS, Malandrini A, Comanducci G, Leuzzi V, Valoppi M, Tessa A et al. Novel SACS mutations in autosomal recessive spastic ataxia of Charlevoix-Saguenay type. Neurology 2004;62:103-106.

92. Ogawa T, Takiyama Y, Sakoe K, Mori K, Namekawa M, Shimazaki H et al. Identification of a SACS gene missense mutation in ARSACS. Neurology 2004;62:107109.

93. Souza JM, Giasson BI, Lee VMY, Ischiropoulos H. Chaperone-like activity of synucleins. FEBS Lett 2000;474:116-119.

94. Goedert M. Alpha-synuclein and neurodegenerative diseases. Nat Rev Neurosci 2001;2:492-500.

95. Polymeropoulos MH, Lavedan C, Leroy E, Ide SE, Dehejia A, Dutra A et al. Mutation in the alpha-synuclein gene identified in families with Parkinson's disease. Science 1997;276:2045-2047.

96. Krueger R, Kuhn W, Mueller T, Woitalla D, Graeber M, Koesel S et al. Ala30Pro mutation in the gene encoding alpha-synuclein in Parkinson's disease. Nat Genet 1998;18:106-108.

97. Rekas A, Adda CG, Aquilina JA, Barnham KJ, Sunde M, Galatis D, Williamson NA et al. Interaction of the molecular chaperone alpha-B-crystallin with alphasynuclein: Effects on amyloid fibril formation and chaperone activity. J Mol Biol 2004;340:1167-1183.

98. Cuervo AM, Stefanis L, Fredenburg R, Lansbury PT, David Sulzer D. Impaired degradation of mutant alpha-synuclein by chaperone-mediated autophagy. Science 2004;305:1292-1295.

99. DiMauro S. Mitochondrial diseases. Biochim Biophys Acta-Bioenergetics 2004;1658: $80-88$.

100. Epstein CJ. Human malformations and their genetic basis. In: Epstein CJ, Erickson RP, Wynshaw-Boris A, eds. Inborn errors of development. Oxford, UK: Oxford University Press, 2004:3-9. 